\title{
O uso da notação bussiness process model and notation (BPMN) como estratégia de qualidade em uma empresa de crédito consignado no norte do Tocantins
}

\author{
The use of bussiness process model and notation (BPMN) as quality \\ strategy in a payroll loans company in north of Tocantins
}

1 Janderson Henrique Mota de Sousa henrique.janderson@gmail.com

1 Mestrado em Demandas Populares e Dinâmicas Regionais pela Universidade Federal do Tocantins (2019). Membro do Grupo de Estudos e Pesquisa em Demandas Populares e Dinâmicas Regionais (GEPDire) da Universidade Federal do Tocantins e do Grupo de pesquisa em Gestão, Inovação, Tecnologia e Educação Socioambiental (GITES) do Instituto Federal de Educação, Ciência e Tecnologia do Tocantins. Universidade Federal do Tocantins.

\section{Resumo}

A notação BPMN é uma das diversas possibilidades de se mapear e padronizar fluxos de processos. 0 mapeamento e a padronização são estratégias para se atingir uma melhor qualidade em produtos, bens e serviços. 0 objetivo deste trabalho é mapear e modelar o fluxo de processos que englobam a venda de produtos consignados em uma empresa de crédito consignado no Norte do Tocantins, visando, dessa forma, integrar o Procedimento Operacional Padrão (POP) que está sendo desenvolvido pela empresa. Metodologicamente, esta pesquisa classifica-se como bibliográfica. Quanto aos procedimentos utilizados, podemos, também, classificá-la como um estudo de caso com natureza qualitativa e com princípios de pesquisa-ação. Quanto aos objetivos, podemos classificá-la como exploratória e descritiva. Com a entrega do fluxo de processos mapeados em nível macro, sugere-se para trabalhos futuros o mapeamento em nível micro.

\section{Palavras-chave:}

Fluxo de processos. Mapeamento de processos. BPMN. Qualidade. Crédito consignado.

\begin{abstract}
The BPMN notation is one of many possibilities for mapping and standardizing process flows. Mapping and standardization are strategies to achieve greater quality in products, goods and services. The objective of this study is to map and model the process flow that includes the sale of payroll products in a payroll loan company in the north of Tocantins, aiming, in this way, to integrate the Standard Operating Procedure (POP) that is being developed by the company. Methodologically, this research is classified as bibliographic, regarding the procedures used we can also classify it as a case study with qualitative nature and with principles of action research. Concerning the objectives, it can be classified as exploratory and descriptive. Delivering the process flow mapped in the macro level, it is suggested for future work the mapping in the micro level.
\end{abstract}

\section{Keywords:}

Process flow. Process mapping. BPMN. Quality. Payroll loan.

Como você deve citar?

SOUSA, Amanda Oliveira de; SANTOS, Jahyra Helena Pequeno dos. Ações afirmativas de gênero na política brasileira: interfaces entre reconhecimento, redistribuição e representação política. Cadernos UniFOA, Volta Redonda (RJ), v. 16, n. 47, p. $101-118$, dez, 2021. 
Pensar o contexto socioeconômico do século XXI requer entender que tanto a sociedade quanto as empresas estão envoltas em um ambiente com grande fluxo de informações digitais (BAUMAN, 1999). Esse grande fluxo é acompanhado de uma tendência: os consumidores finais estão cada vez mais próximos das organizações. E, por esse motivo, conseguem ter um poder maior de persuasão sobre produtos, bens e serviços que são entregues pelas organizações (KOTLER; KARTAJAYA; SETIAWAN, 2017).

Conceitos como network, digitalização, marketing digital, estratégia mercadológica e empowerment ganham uma conotação importante no dia a dia das entidades organizacionais, e, em meio a esse contexto, cada vez mais, torna-se necessário que as organizações padronizem seus processos, objetivando, dessa forma, parâmetros de qualidade que atendam às expectativas desse novo perfil de cliente. (KOTLER; KARTAJAYA; SETIAWAN, 2017).

Com um mercado cada vez mais acirrado, Paludo (2019) compreende que pensar estrategicamente a qualidade será um dos maiores diferencias que as organizações poderão ofertar aos seus clientes. Não distante do pensamento de Paludo (2019), Chiavenato e Sapiro (2009) destacam que, a partir do advento das relações digitais, os consumidores anseiam por padrões de qualidade cada vez melhores.

Uma das formas de melhorar a qualidade dos produtos, bens e serviços é a definição de parâmetros que deverão compor o Procedimento Operacional Padrão (POP). O POP é composto por um conjunto de informações que detalham a operação de um fluxo de processos. Uma das possíveis formas de construir esse procedimento é por meio de notações que evidenciarão, graficamente, por meio de símbolos pré-estabelecidos, a maneira correta de se executar um fluxo de processos.

Existem várias notações que servem como método para construção de POP, uma delas é a Bussiness Process Model and Notation (BPMN). A notação BPMN pode ser compreendida como um "conjunto de elementos que são estruturados em um diagrama denominado de DPN - Diagrama de processos de negócio, em que setores de uma empresa [...] organizados em raias por onde atividades e processos são descritos" (TOLFO; MEDEIROS; MOMBACH, 2013, p. 07). Uma das principais finalidades do uso de notação BPMN é servir como mecanismo de criação de processos.

Lobo, Conceição e Oliveira (2018) entendem que a técnica de notação de modelagem BPMN serve para representar graficamente o fluxo de operações e suas respectivas atividades. Os referidos autores ainda destacam que essa técnica é extremamente versátil ao permitir a identificação de processos não efetivos ou processos que necessitem de reformulações.

Lobo, Conceição e Oliveira (2018) inferem que o BPMN pode e deve ser usado em diversos contextos, como, por exemplo, em ambientes que necessitem de uma melhora contínua. Em pequenas, médias e grandes empresas que estão em ambiente altamente dinâmicos, essa técnica permite uma maior integração entre os diversos atores (stakeholders), ao permitir que eles compreendam o funcionamento exato dos processos (TOLFO; MEDEIROS; MOMBACH, 2013).

Buscando entender o funcionamento de um processo longo e complexo, este estudo tem por objetivo geral mapear e modelar o fluxo de processos que englobam a venda de produtos consignados, visando, dessa forma, integrar o POP que está sendo desenvolvido pela empresa. Como objetivos específicos, tem-se: analisar as etapas que compõem o fluxo de venda de produtos consignados; diagramar o fluxo de processos da venda de produtos consignados. 
O procedimento metodológico deste estudo é baseado em uma pesquisa bibliográfica, um estudo de caso com natureza qualitativa e com princípios de pesquisa-ação. Gil (2010) afirma que a pesquisa bibliográfica tem por intenção fundamentar, validar e suportar, teoricamente, o objeto de pesquisa. Esse tipo de pesquisa é pautado em uma revisão de outras pesquisas que já foram publicadas. Essas publicações, conforme registra o autor, podem ser em meios físicos e digitais. Neste trabalho, a pesquisa bibliográfica levou dados, informações e conhecimentos que serviram para fundamentar, validar e suportar o objeto de pesquisa, que é o fluxo de processos que são inerentes à venda de produtos consignados em uma empresa de créditos no norte do Tocantins.

No entanto, por causa da peculiaridade do objeto de estudo deste artigo, fez-se necessário o uso de um estudo de caso. Yin (2010) e Gil (2010) interpelam que o estudo de caso é uma investigação realizada de forma empírica acerca de um ou mais fenômenos contemporâneos. Segundos os referidos autores, esse tipo de estudo proporciona a possibilidade de se compreender melhor os limites entre o fenômeno e o contexto contemporâneo. Especificamente neste estudo, esses limites são vistos na Figura 1 , que apresentará toda a diagramação dos processos que compõem a venda de produtos consignados.

Tripp (2005) destaca que a pesquisa-ação é ideal para a compreensão, para a análise e para a problematização de processos visando, por sua vez, uma transformação nas práticas que são encerradas em um determinado lugar. Neste estudo, percebe-se que a pesquisa-ação encerra novas práticas no ambiente laboral. Essas novas práticas decorreram dos fluxos de processos que serão normatizados no procedimento operacional padrão que está em processo de criação pela organização.

Este estudo é classificado, quanto aos objetivos, como uma pesquisa exploratória e descritiva. Severino (2007) infere que a pesquisa exploratória serve para levantar informações sobre um determinado objeto de pesquisa e, se possível, constituir uma ou mais hipóteses. Gil (2010) percebe que a pesquisa descritiva vai possibilitar o aprofundamento de características, tais como: sexo, idade, nível de escolarização, dados socioeconômicos, dados sociodemográficos, etc.

Para o mapeamento do fluxo de processos e a sua diagramação, foi utilizada a ferramenta gratuita HEFLO. Essa ferramenta é disponibilizada em seu site e pode ser compreendida como uma plataforma única e integrada para gerenciar, modelar e otimizar fluxos de processos. Ela permite o uso de várias notações. No entanto, conforme disponibilizado em seu site, é ideal para a notação BPMN.

A organização em si é composta por dois grupos de profissionais: internos e externos. Os profissionais internos mantêm vínculos empregatícios legais. Os profissionais externos, conhecidos como "corretores", não apresentam vínculo empregatício com a organização, mas apenas apresentam uma relação de "prestação de serviços". Internamente, quatro pessoas são responsáveis pelo fluxo de processos. Externamente, segundos dados divulgados pela organização, existem cerca de vinte corretores.

Especificamente, neste trabalho, será privilegiada a visão dos colaboradores que mantêm vínculo empregatício com a organização, de pequeno porte e atuante na região de Araguaína - Tocantins. Essa região é reconhecida pelo forte comércio de produtos, bens e serviços e pelo setor de carnes (SOUSA, 2019).

\section{O SETOR DE CRÉDITOS CONSIGNADOS E A COMPLEXIDADE DE SEUS PROCESSOS}

O setor de crédito consignado é um ramo que vem crescendo muito nos últimos dez anos no Brasil, devido às taxas de juros serem as mais baixas disponibilizados em nosso mercado (BACEN, 2018). É 
compreendido atualmente como "uma modalidade de crédito em que o desconto da prestação é feito diretamente na folha de pagamento ou de benefício previdenciário do contratante" (BACEN, 2018, p. 110).

O ramo dos produtos consignados é relativamente novo no Brasil. Sua criação culmina com a Lei 10.820, de 17 de dezembro de 2003, que dispõe sobre a autorização para desconto de prestações em folha de pagamento (BRASIL, 2003). Essa lei proporcionou a criação de um mercado que movimentou, entre março de 2007 a abril de 2018, uma cifra equivalente a 350 bilhões de reais (BACEN, 2018).

Por se tratar de um mercado que é regulamento por uma vasta legislação, é necessário que as diversas partes que atuam nele tenham uma noção mais aprofundada sobre o funcionamento de diversas instituições, como, por exemplo, a Empresa de Tecnologia e Informações da Previdência (DATAPREV), o Instituto Nacional do Seguro Social (INSS), o Sistema de Gestão de Acesso do Ministério do Planejamento (SIGAC), etc.

Pontes e Lopes (2017, p. 33) destacam que o ramo de crédito consignado no Brasil cresce bastante "por conta da existência de uma ampla rede de correspondentes em todos os municípios brasileiros". E, por causa dessa grande rede, faz-se necessária uma maior atuação dos órgãos regulamentadores visando, portanto, a boas práticas no mercado.

Nem sempre essas regulamentações tornam o fluxo de tomada de crédito mais rápido. Grande parte dessas regulamentações surgem como prevenção e combate às fraudes constantes nesse mercado. Somente no âmbito INSS, nos últimos três anos, surgiram vários dispositivos que visam combater ativamente a onda crescente de fraudes no setor. A exemplos desses dispositivos, as Instruções Normativas (IN) IN-100 e IN-107 regulamentam boas práticas e definem novos procedimentos para a contratação de empréstimos consignados.

Com a regulamentação das INs, não somente os bancos, mas também os correspondentes e promotores bancários tiveram que se ajustar às rígidas normas de disponibilização de crédito consignado. Na prática, elas obrigaram esses atores a se modernizarem. No entanto, o fluxo de processos para aprovação de crédito ficou maior e mais complexo para as pessoas que operam os diversos sistemas das organizações bancárias.

Estrategicamente, uma das melhores formas de lidar com esse novo fluxo de processos é por meio do treinamento dos agentes de créditos. Esses agentes são os que trabalham diretamente na venda, na implantação e na auditoria de processos que englobam os produtos consignados. Eles são obrigados, por legislação específica, a passar por um curso de treinamento e uma prova de certificação. Essa certificação é de responsabilidade da Associação Nacional dos Profissionais e Empresas Promotoras de Crédito e Correspondentes no País (ANEPS).

No entanto, para que esse treinamento possa acontecer, é necessário o mapeamento do fluxo de processos que envolvem os produtos consignados. Nesse sentido, a notação BPMN pode propiciar meios para a diagramação de vários processos dentro do âmbito de vários atores, pois o fluxo de processos para tomada e aprovação de crédito consignado não ocorre de forma isolada. Conforme 0 BACEN (2018), esse processo ocorre naturalmente entre algumas instâncias: 1 - cliente; 2 - financeira; 3 - órgãos averbadores de crédito.

E, por não ocorrer dentro de uma mesma instância, o processo de tomada e aprovação de crédito torna-se complexo para os atores que ofertam esse tipo de crédito. Tal complexidade é o fator que motivou este estudo. Conforme destacado pelo BACEN (2018), cada uma dessas instâncias tem atribuições 
e papéis diversificados. Torna-se, então, necessário que os agentes compreendem as diversas estruturas que vão intermediar o processo de aprovação desse crédito.

Conforme se verá na seção de análise, a notação BPMN possibilita a visualização gráfica dos processos que compõem a tomada e a aprovação do crédito consignado. Dessa maneira, é possível a padronização de boas práticas dentro das organizações. A adoção dessas práticas levará, consequentemente, a uma percepção de satisfação dos serviços que são prestados pelos agentes e pelas financeiras como um todo.

Pensando nessas boas práticas, torna-se necessária a modelagem dos processos que são inerentes ao setor de crédito consignado, facilitando, dessa forma, que os diversos atores compreendam totalmente o sequenciamento de todas as tarefas e etapas. Na próxima seção, será discutida a notação BPMN como possibilidade de estratégia de qualidade para a modelação e diagramação de fluxos de processos.

\section{O USO DA NOTAÇÃO BPMN COMO ESTRATÉGIA DE QUALIDADE NA MODELAGEM DE PROCESSOS}

Chiavenato e Sapiro (2009) percebem que os ambientes empresarial e industrial (particularmente o brasileiro) estão sofrendo constantes mudanças. Grande parte dessas mudanças são advindas dos fatores tecnológicos e da forma como os consumidores finais estão se relacionando com esses fatores.

A tendência atual é que os mercados fiquem cada vez mais acirrados e orgânicos (CHIAVENATO; SAPIRO, 2009). Acirrados devido à concorrência, que hoje é global, e orgânicos por apresentarem características de mercados dinâmicos, abandonando, portanto, as características de mercados conservadores. As empresas, para se manterem competitivas nesses mercados dinâmicos e também nos mercados altamente dinâmicos, precisam rever suas estratégias e seus procedimentos, pois o público-alvo demanda isso (CHIAVENATO; SAPIRO, 2009).

Uma das formas possíveis de melhorar a qualidade dos produtos, bens e serviços ofertados é a padronização e o aperfeiçoamento dos fluxos de processos. Nesse sentido, surge a Gestão de Processos de Negócio (GPN), que também é conhecida como Business Process Management (BPM). Lobo, Conceição e Oliveira (2018) destacam que o BPM e a GPN surgem como proposta frente às novas demandas dos mercados, possibilitando, portanto, uma maior integração entre os vários setores de uma ou de mais organizações.

Jacoski e Grzebieluchas (2011) interpretam que, ao se delimitar os processos, é possível identificar aqueles que necessitam de correção. Para tal identificação, segundo os autores, é necessário o conhecimento sobre todos os recursos de entrada, de saída e os transformadores de cada tarefa. Dessa forma, é possível aumentar a competitividade no mercado e, por consequência, a qualidade do produto e o retorno financeiro para a organização.

O BPMN possibilita a diagramação de todos as tarefas que compõem um fluxo. Dávalos, Luna e Souza $(2015$, p. 155) inferem que o BPMN serve para permitir a integração nas empresas por meio de

[...] todos os elementos que a compõem, sejam eles homens, máquinas ou sistemas computacionais, (e que) possam trocar informações e interagir numa profundidade além da simples troca física de dados. Isto passa necessariamente pela consideração de uma visão holística, significando o desenvolvimento de uma imagem única e integrada da organização. 
Esses autores (2015) compreendem, portanto, que a notação BPMN vai além de um simples diagrama de processos, ao permitir uma integração profunda e complexa, tornando, assim, a organização mais orgânica possível. Compreender o funcionamento desses processos passa a ser uma das variáveis mais importantes no planejamento estratégico das entidades organizacionais.

O surgimento da notação BPMN ocorreu a partir da necessidade de se padronizar as notações que eram usadas por grandes empresas, como, por exemplo, a IBM, a Fujitsu e a SAP (DÁVALOS; LUNA; SOUZA, 2015). Cada uma dessas empresas possuía suas próprias notações, e, pela falta de padronização, não era possível uma total integração de projetos entre as organizações diferentes.

Pizza (2012) percebeu, em seu trabalho de conclusão de curso, que usar o BPMN como estratégia de qualidade permite às organizações maior valor agregado aos clientes. Para o referido autor, ao adotarem a técnica, as organizações passam a proporcionar boas práticas organizacionais, e, dessa maneira, os processos se tornam mais eficazes, eficientes e efetivos.

Segundo a Escola de Serviço Público do Espírito Santo (ESESP) o BPMN, quando usado estrategicamente, permite: 1 - a criação de valor para clientes; 2 - uma gestão eficiente do negócio, ao se olhar para os processos que o compõem; 3 - foco sempre nos clientes; 4 - eliminação de redundâncias desnecessárias; 5 - redução próxima a zero de desperdícios e defeitos; 5 - maleabilidade na transformação dos negócios por meio de processos; 6 - reconhecimento dos diversos stakeholders dos processos (ESESP, 2016) .

\section{O FLUXO DE PROCESSOS EM UMA EMPRESA DE CRÉDITOS CONSIGNADOS NO TOCANTINS.}

Conforme destacado anteriormente, o processo escolhido para a diagramação, neste estudo, foi o processo de venda de produtos consignados. 0 referido processo acontece, conforme apresentado na Figura 1, em quatro instâncias distintas: cliente, loja, promotora e órgão averbador. Logo a seguir, a Figura 1 apresenta o processo que foi diagramado: 
Figura 01: 0 fluxo do processo de venda dos produtos consignados.

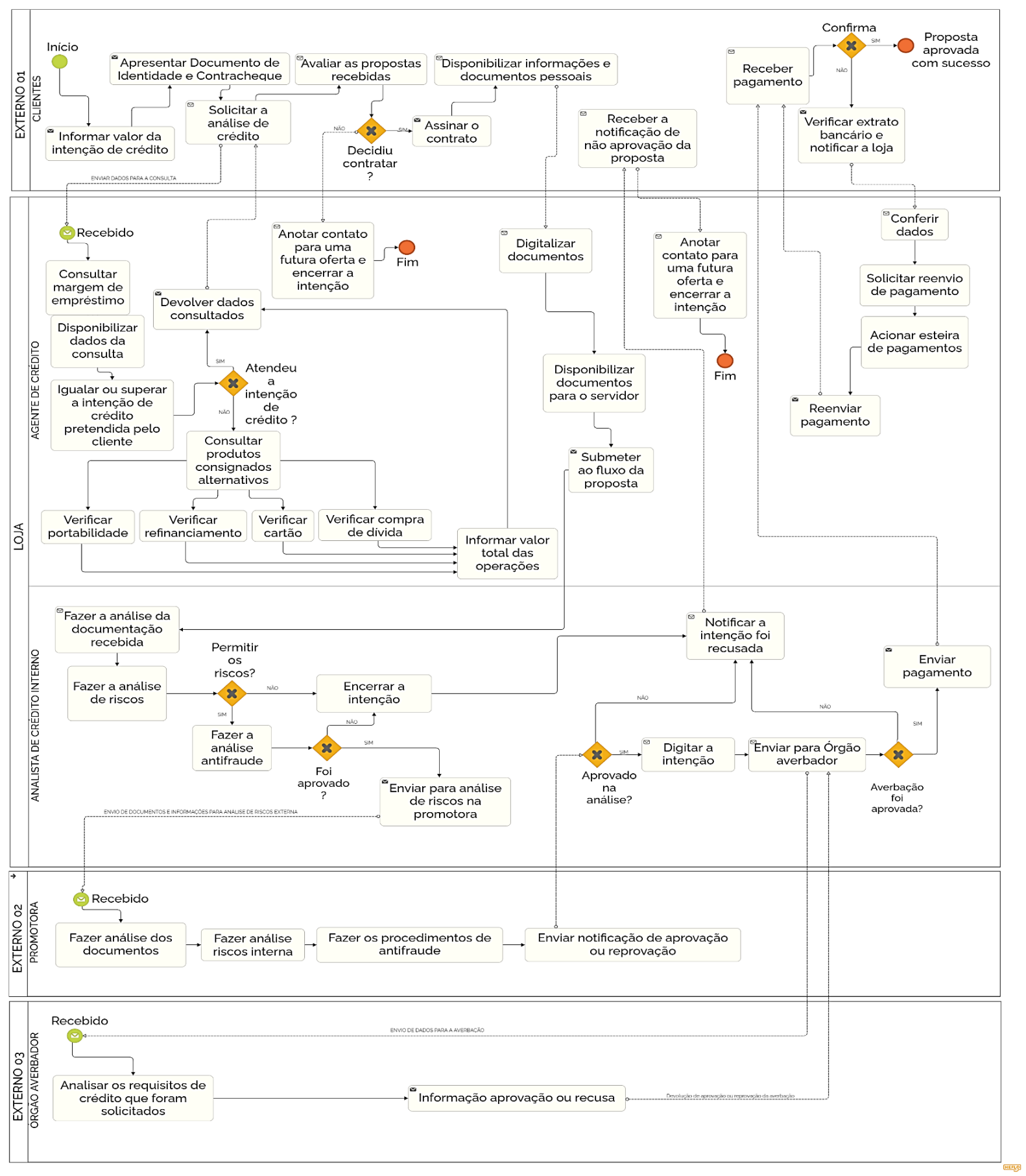

Fonte: Elaborado pelo autor.

Ao se observar para a Figura 1, é possível perceber o que o BACEN (2018) destaca sobre a complexidade dos processos que compõem a venda de produtos consignados. A principal variável que corrobora com esse entendimento é o fato de 04 instâncias distintas serem necessárias para a aprovação da linha de crédito. Cada uma dessas instâncias é representada, graficamente, por uma das quatro raias disponíveis na Figura1.

A primeira raia destacou o fluxo de processos que são pertinentes ao cliente. As atribuições iniciais dele são informar o valor da intenção de crédito e apresentar os documentos essenciais para 
a análise de crédito, que ocorrerá logo em seguida. Esse primeiro contato é de suma importância para que $o$ agente de crédito possa compreender qual a melhor estratégia para atingir a importância que 0 cliente deseja dentro dos limites de crédito disponíveis para ele.

$\mathrm{Na}$ ação "solicitar a análise de crédito", percebe-se que se iniciam vários processos dentro da instância "loja". A partir de sistemas específicos para análise e viabilidades de crédito, os limites disponíveis são informados ao agente de crédito e este, por sua vez, informa os valores que podem ser disponibilizados para o cliente. Caso o cliente aceite a proposta, assinará um contrato de crédito e disponibilizará ao agente seus documentos e informações pessoais.

Os próximos eventos, após a disponibilização dos documentos e informações pelo cliente, são de responsabilidade das outras três raias. Um novo fluxo de processos é iniciado a partir desse momento: a digitalização de documentos. Esse processo se ocupa do fluxo de processos conhecido como formalização de documentos da proposta. Disponibiliza-se, nesse processo, os documentos para as análises de riscos interna e externa. Essas análises são de responsabilidade de duas instâncias distintas: a interna, pela própria loja, e a externa, pela promotora.

Caso os documentos do processo de formalização sejam aprovados com sucesso pelas análises de riscos interna e externa, o fluxo de processos prossegue para a fase de implantação da proposta nos sistemas bancários. Os processos que compõem a análise de riscos não foram detalhados na Figura 1 , pois ainda serão diagramados em um momento posterior e incluirá o procedimento operacional padrão da organização estudada.

Com a aprovação de risco e a digitação nos sistemas bancários, a proposta de crédito segue para análise interna dos bancos, que visa à prevenção de fraudes e à conferência de todos os requisitos de averbação demandados por cada convênio. Essa análise é automática. Conforme destacado na Figura 1 , a proposta de crédito segue para a averbação. 0 processo de averbação é um processo de conferência e aprovação da margem e dos requisitos de crédito pelo mutuário. A figura 1 destaca que, na ação "enviar propostas para a averbação", uma nova instância surge no processo de vendas de produtos consignados: o órgão averbador. 0 fluxo de processos, nessa instância, constitui: 1 - analisar os requisitos de crédito que foram solicitados; 2 - aprovar ou recusar; 3 - informar aprovação ou reprovação.

O primeiro processo da raia "órgão averbador" analisa se o mutuário possui a margem solicitada e se ele está ativo na base do sistema. Com base nas informações disponibilizadas pelos sistemas internos ao órgão, deve-se prosseguir, disponibilizando os dados de aprovação ou de recusa da intenção de crédito inicial. Esses dados são devolvidos para a instância "loja", que é responsável pela venda, implantação e acompanhamento da intenção de crédito.

Caso seja constatada a aprovação da averbação, o próprio sistema bancário disponibiliza o crédito na conta corrente (em alguns casos, na conta poupança ou conta de pagamentos) que consta no contracheque do cliente. Esse envio é automático em quase todos os sistemas bancários e não necessita de aprovação ou reprovação por parte do "analista de crédito interno" da "loja".

Com o pagamento enviado, conforme se observa na raia "cliente", o cliente recebe o pagamento e o processo está concluído. Em caso de algum problema na conta disponibilizada pelo cliente ou um erro de qualquer natureza, um processo de recuperação de envio do crédito é acionado. 0 cliente disponibiliza um extrato de sua conta e uma conferência de dados é feita. Ocorre, nesse processo, uma solicitação de reenvio dos dados de créditos e, na etapa de "acionar a esteira de pagamentos", uma nova conta pode ser cadastrada. Por fim, uma ordem de crédito é reenviada pelo "robô de pagamento" e o crédito é disponibilizado ao cliente. Dessa maneira, o fluxo de processos de venda de produtos consignados é finalizado. 
O mercado de produtos consignados no Brasil apresenta algumas complexidades, devido à necessidade de atuação de vários atores. Conforme visto neste artigo, esses atores são divididos em quatro instâncias: cliente, loja, promotora e órgão averbador. Cada instância apresenta processos internos que são essenciais para a aprovação da intenção de crédito, demandada pelo cliente.

Teoricamente, este estudo permitiu mostrar que é possível usar a notação BPMN como estratégia para atingir qualidade. Essa estratégia só é viável devido à padronização dos processos que fornecerão, ao usuário/cliente final, produtos, bens e serviços com qualidade elevada.

Analiticamente, este trabalho disponibilizou a Figura 1, que revelou a criticidade do fluxo de processos pertinentes à venda de produtos consignados. Com a diagramação desse fluxo, foi possível concluir o objetivo geral, que é a entrega desse fluxo de processos e, consequentemente, atingir os dois objetivos específicos deste trabalho: analisar as etapas que compõem o fluxo de venda de produtos consignados; diagramar o fluxo de processos da venda de produtos consignados.

Ao se observar a Figura 1, é possível perceber que o mapeamento desses processos revela, em nível macro, as diversas etapas/atividades que são peculiares ao processo estudado, como também são perceptíveis a necessidade de outros mapeamentos que possam sistematizar o fluxo de processos em nível micro. Esse detalhamento em nível micro está em construção pela organização estudada. Uma possível sugestão para futuros trabalhos seria a disponibilização do mapeamento desses processos em nível micro.

\section{REFERÊNCIAS}

BANCO CENTRAL DO BRASIL. Empréstimo consignado: características, acesso e uso. In: Relatório da cidadania financeira. - Brasília: BACEN, 2018. Disponível em: https://www.bcb.gov.br/Nor/relcidfin/docs/ art7_emprestimo_consignado.pdf. Acesso em: 27 set. 2020.

BRASIL. Lei 10.820, 10 de dezembro de 2003. Dispõe sobre a autorização para desconto de prestações em folha de pagamento, e dá outras providências. Brasília, DF: Presidência da República, 2003. Disponível em: http://www.planalto.gov.br/ccivil_03/leis/2003/l10.820.htm. Acesso em: 27 set. 2020.

BAUMAN, Zygmunt. Globalização: as consequências humanas. Rio de Janeiro: Jorge Zahar Editor, 1999.

CHIAVENATO, Idalberto; SAPIRO, Arão. Planejamento estratégico. 2. ed. Rio de Janeiro: Elsevier, 2009.

DÁVALOS, Ricardo V.; LUNA, Mônica M.; SOUZA, Deyvid P. O uso da notação BPMN no ensino de simulação de sistemas. Iberoamerican Journal of Industrial Engineering, Florianópolis, SC, Brasil, v. 7, n. 14, p. 151-166. Disponível em: http://incubadora.periodicos.ufsc.br/index.php/IJIE/article/view/3677/pdf_109. Acesso em: 23 set. 2020.

Escola de Serviço Público do Espírito Santo. Introdução ao BPM e modelagem com BPMN 2.0. Vitória: ESESP, 2016. 144 p.

GIL, Antônio Carlos. Como elaborar projetos de pesquisa. 5. ed. São Paulo: Atlas, 2010.

INSTITUTO NACIONAL DO SEGURO SOCIAL. Instrução Normativa Nº 100, De 28 De Dezembro De 2018. Altera dispositivos da Instrução Normativa INSS/PRES $n^{\circ}$ 28, de 16 de maio de 2008. Brasília, DF. 
Disponível em: https://www.in.gov.br/materia/-/asset_publisher/Kujrw0TZC2Mb/content/id/57496300/ do1-2018-12-31-instrucao-normativa-n-100-de-28-de-dezembro-de-2018-57496089. Acesso em: 27 set. 2020.

INSTITUTO NACIONAL DO SEGURO SOCIAL. Instrução Normativa N 107, de 22 De Julho De 2020. Altera dispositivos da Instrução Normativa INSS/PRES n ${ }^{\circ}$ 28, de 16 de maio de 2008. Brasília, DF. Disponível em: https://www.in.gov.br/en/web/dou/-/instrucao-normativa-n-107-de-22-de-julho-de-2020-268191975. Acesso em 27 set. 2020.

JACOSKI, Claudio Alcides; GRZEBIELUCHAS, Tiago. Modelagem na contratação de projetos utilizando os conceitos de BPM - gerenciamento de processos de negócio. Produto \& Produção, vol. 12, n. 3, p. 2937, out. 2011. Disponível em: https://seer.ufrgs.br/ProdutoProducao/article/view/9538/13957. Acesso em: 23 set. 2020.

KOTLER, P.; KARTAJAYA, H.; SETIAWAN, I. Marketing 4.0. $1^{\text {a }}$. ed. Rio de Janeiro: Editora Sextante, 2017. 208 p.

PONTES, Alcioni de Souza; LOPES, Paloma de Lavor. Estratégias de captação e fidelização de cliente de crédito consignado. Revista Valore, Volta Redonda, 2 (1), p. 34-50, Junho/2017. Disponível em: https:// revistavalore.emnuvens.com.br/valore/article/view/29. Acesso em: 27 set. 2020.

TOLFO, C.; MEDEIROS, Thiarles S.; MOMBACH, Jaline G. Modelagem de processos com BPMN em pequenas empresas: um estudo de caso. In: XXXIII ENEGEP - Encontro Nacional De Engenharia De Produção. 2013. Salvador, BA, Brasil. Anais XXXIII Encontro Nacional de Engenharia de Producao: A Gestão dos Processos de Produção e as Parcerias Globais para o Desenvolvimento Sustentável dos Sistemas Produtivos. Salvador: ABEPRO, 2013. p. 01-16. Disponível em: http://www.abepro.org.br/ biblioteca/enegep2013_TN_STO_177_013_22720.pdf. Acesso em: 23 set. 2020.

LOBO, Cicero V. F.; CONCEIÇÃO, Roberta D. P; OLIVEIRA, Saulo B. Gestão por Processos: Um Estudo de Aplicação da Notação BPMN em uma Empresa de Serviços do Setor de Óleo e Gás. Revista IPTEC, v. 6, n. 1, p. 94-110, jun. 2018. ISSN 2318-9851. Disponível em: http://www6.uninove.br/ojs/journaliji/index. php/iptec/article/view/133. Acesso em: 23 set. 2020. doi:10.5585/iptec.v6i1.133.

PIZZA, William Roque. A metodologia Business Process Management (BPM) e sua importância para as organizações. 2012. $37 \mathrm{f}$. Trabalho de Conclusão de Curso (Curso de Tecnologia em Processamento de Dados) - Faculdade de Tecnologia de São Paulo-FATEC, São Paulo, SP, 2012.

SEVERINO, Antônio Joaquim. Metodologia do trabalho científico. 23. ed. rev. e atual. São Paulo: Cortez, 2007.

SOUSA, J. H. M. Ruas de comércio: avenida Cônego João Lima e as vivências laborais de vendedores de confecções em Araguaína - Tocantins. Dissertação de mestrado - Universidade Federal do Tocantins, Araguaína, 2019.

TRIPP, David. Pesquisa-ação: uma introdução metodológica. Educação e Pesquisa, São Paulo, v. 31, n. 3, p. 443-466, set./dez. 2005. Disponível em: https://www.scielo.br/pdf/ep/v31n3/a09v31n3. Acesso em: 12 out. 2020.

YIN, R. Estudo de caso: planejamento e métodos. 4. ed. Porto Alegre: Bookman, 2010. 